\title{
Formação em Fisioterapia no Estado da Bahia-:Análise dos Aspectos Éticos e Humanísticos dos Projetos Pedagógicos dos Cursos
}

\author{
Sady, Cleber Murilo Pinheiro; Santos, Fabiane Costa \\ Universidade Federal da Bahia-Instituto de Humanidades Artes e Ciencias Professor Milton Santos-Eisu-Ihac - \\ ptsport@uol.com.br
}

INTRODUÇÃO: a compreensão da trajetória percorrida pela área de Fisioterapia é essencial na identificação e elaboração de propostas a serem incorporadas nos projetos pedagógicos dos cursos(PPCs) para a formação e preparação adequada do profissional para o mercado de trabalho. ao longo de 42 anos de formação em Fisioterapia na Bahia, a profissão apresentou diversas etapas, cada qual com sua particularidade e contextualização com o desenvolvimento das profissões de saúde. em cada período da história, a formação em Fisioterapia na Bahia passou por diferentes modelos educacionais, porém sempre adstrito ao modelo biomédico com um forte vínculo com a reabilitação . Os currículos e conteúdos programáticos direcionavam principalmente para o atendimento às pessoas com alguma deficiência física. As mudanças dos currículos e dos PPCs de Fisioterapia a partir da publicação das Diretrizes Curriculares Nacionais (DCNs) apontam para a necessidade de transformação do perfil dos trabalhadores em saúde com base nos pressupostos do sistema único de saúde (SUS) e no conceito ampliado de saúde. Aspectos éticos e humanísticos devem estar presentes nos PPCs objetivando preparar os trabalhadores da área para fazer frente aos desafios da atenção aos usuários do SUS. OBJETIVOS: o objetivo desse estudo foi analisar os PPCs dos cursos de Fisioterapia na Bahia, comparando universidades públicas e privadas. MÉTODOS: Trata-se de um estudo descritivo de corte transversal realizado entre os meses de agosto a dezembro de 2013. Foi feita análise documental utilizando como referência os PPCs de duas universidades públicas e duas privadas, onde foram buscadas as expressões: ética, ética profissional, bioética, humanização e formação humanista. Foram também analisados através da investigação os aspectos: Objetivo do Curso e Perfil do Egresso: na analise dos PPCs, as expressões ética e ética profissional foram encontradas em todos os cursos. Já a expressão humanização foi encontrada somente nas universidades públicas. a expressão formação humanista não foi encontrada em nenhum dos projetos avaliados. As expressões encontradas no entanto, não foram suficientes para demonstrar a dimensão exata que cada proposta contida nos PPCs nos aponta quanto a um caminho para a formação de profissionais com formação ética e humanista, aptos a atenderem as novas demandas dos serviços de saúde, com foco no SUS e a mudanças nas práticas do cuidado em saúde. CONCLUSÃO: o estudo permitiu analisar como os termos formação ética e humanista se inserem nos PPCs e como as universidades estão tentando adequar os seus currículos às DCNs. Aspectos como formação ética e humanista ainda são tratados de forma incipiente, principalmente nas universidades privadas. Além de estarem presentes nos textos dos PPCs é necessário que tais expressões estejam contextualizadas com os cenários de práticas, demonstrando como serão trabalhadas principalmente em relação aos equipamentos públicos de saúde.

Sady, Cleber Murilo Pinheiro; Santos, Fabiane Costa. Formação em Fisioterapia no Estado da Bahia-:Análise dos Aspectos Éticos e Humanísticos dos Projetos Pedagógicos dos Cursos. In: Anais do Congresso Internacional de Humanidades \& Humanização em Saúde [= Blucher Medical Proceedings, num.2, vol.1]. São Paulo: Editora Blucher, 2014.

ISSN 2357-7282

DOI 10.5151/medpro-cihhs-10810 